\title{
Correlações de Pearson e canônica entre componentes da matéria seca da forragem e sementes de azevém ${ }^{1}$
}

\author{
Liziany Müller ${ }^{2 *}$, Paulo Augusto Manfron², Sandro Luís Petter Medeiros², \\ Maria Helena Rigão², Andriéli Hedlund Bandeira², Cléber José Tonetto \\ Durval Dourado-Neto ${ }^{4}$
}

\begin{abstract}
RESUMO - O melhoramento genético de plantas forrageiras é fundamental para a intensificação da pecuária. Este trabalho foi realizado com o objetivo de avaliar a correlação simples de Pearson entre os componentes produtivos da matéria seca da forragem e de sementes para genótipos de azevém. Cinco genótipos de azevém, cultivados em cinco datas de semeadura, com diferentes números de cortes (variando de um a quatro), foram usados no delineamento blocos ao acaso com quatro repetições em Santa Maria, RS. Pastagens de azevém com uma menor produtividade total de matéria seca, mas composta por uma quantidade maior de folhas e menor de colmo, com maior teor proteico e menor teor de fibra em detergente neutro determinam maior rendimento de sementes, comprimento de espigas e peso de mil sementes, e menor número de espigas. A associação entre componentes do rendimento da matéria seca e do rendimento de semente é critério de fundamental importância na seleção de genótipos para o azevém, pois o rendimento de sementes correlaciona-se positivamente com a produção de matéria seca de folhas, teor de proteína bruta, comprimento de espiga e peso de mil sementes.
\end{abstract}

Termos para indexação: correlação linear, espiga, melhoramento de plantas, Lolium multiflorum, proteína bruta.

\section{Pearson's simple and canonical correlations between components of forage dry matter and seeds of ryegrass}

\begin{abstract}
Forage breeding is key to improving livestock management and the objective of this study was to evaluate Pearson's simple correlation between the yield components of forage dry matter and grain in ryegrass. Five ryegrass genotypes, planted on five dates and cut from one to four times, were set out in a complete randomized block design. Ryegrass forage with a lower dry matter production, but with more leaves, fewer culms, higher protein and less fiber content, produces a higher grain yield, spike length, thousand grain weight and lower spike number. The association between the yields of dry matter and grain components is an important criterion for selecting ryegrass genotypes, since grain yield is positively correlated with leaf dry matter, gross protein content, spike length and thousand grain weight.
\end{abstract}

Index terms: linear correlation, spike, plant breeding, Lolium multiflorum, crude protein.

${ }^{1}$ Submetido em 03/06/2010. Aceito para publicação em 27/06/2011.

${ }^{2}$ Centro de Ciências Rurais, Universidade Federal de Santa Maria, 97105-900 Santa Maria, RS, Brasil.

${ }^{3}$ Instituto Federal de Educação Ciência e Tecnologia Farroupilha, 97420-000 São Vicente do Sul, RS, Brasil.
${ }^{4}$ Departamento de Produção Vegetal, USP/ESALQ, Caixa Postal 9, 13418-900 - Piracicaba, SP, Brasil.

*Autor para correspondência <lizianym@hotmail.com> 


\section{Introdução}

O melhoramento genético de forrageiras é fundamental na intensificação da pecuária, e não visa apenas cultivares mais produtivas, mas com maior eficiência na produção animal, portanto, é necessário melhorar simultaneamente mais de uma característica. Flores et al. (2008) relatam que os principais objetivos do melhoramento do azevém são a tolerância ao frio, o aumento na produção de forragem e seus componentes nutricionais, e o aumento na produção de sementes.

O azevém, após sua introdução no país, sofreu intensa seleção natural que lhe conferiu a condição de espécie espontânea com enorme adaptação e disseminação, no entanto, no Sul do Brasil, muito pouco tem sido feito em relação ao melhoramento genético de azevém (Freitas et al., 2003; Noro et al., 2003). Este fato é comprovado, conforme Freitas et al. (2003), pela identificação do azevém no sistema de produção oficial de sementes do estado do Rio Grande do Sul como "Cultivar Comum RS".

A associação entre características de interesse econômico é importante no melhoramento genético, principalmente no estudo das respostas correlacionadas, pois podem possibilitar a identificação de modificações que ocorrem em um determinado caráter em função da seleção praticada em outro (Cruz e Regazzi, 1997). Os autores ainda relatam que os coeficientes de correlação simples, apesar de serem de grande utilidade na quantificação da magnitude e direção das influências de fatores na determinação de caracteres complexos, não dão a importância relativa dos efeitos diretos e indiretos destes fatores.

Identificar e quantificar essa associação entre características produtivas e qualitativas da matéria seca e do rendimento de sementes em azevém é importante para promover seleção mais eficiente, visando atender a maior parte dos objetivos do melhoramento genético em azevém. Uma ferramenta que possibilita o estudo da associação entre dois grupos de variáveis é a análise de correlação canônica (Cruz e Regazzi, 1997), e assim auxiliar na seleção de um ideótipo de planta mais adequado.

A análise de correlação canônica constitui uma maneira simples de reduzir as complexidades envolvidas em relacionar dois conjuntos de variáveis (Trugilho et al., 2003). Com ela pode-se estimar a máxima correlação entre dois complexos de variáveis, compostos por combinações lineares dos vários caracteres que os constituem, e permite avaliar as inter-relações entre dois complexos determinados por um número arbitrário de caracteres, sendo muito utilizada em estudos exploratórios com grande número de variáveis, mas que podem estudar aquelas combinações lineares cuja correlação é mais elevada (Cruz e Regazzi, 1997; Silva et al., 2007).

A maximização da técnica representa uma tentativa de concentrar uma relação de alta dimensão entre dois grupos de variáveis em poucos pares de variáveis canônicas, sendo baseada na determinação de variáveis canônicas ortogonais em cada conjunto de variáveis e por isso as variáveis em cada conjunto devem ser linearmente independentes (Trugilho et al., 2003). Segundo a classificação proposta por Kendal (1980), a análise de correlação canônica é uma técnica de avaliação da interdependência entre grupos de variáveis.

O objetivo no trabalho foi avaliar a correlação simples de Pearson e a correlação canônica entre dois grupos de caracteres: componentes produtivos da matéria seca da forragem e do rendimento de sementes de azevém.

\section{Material e Métodos}

O experimento foi realizado no Departamento de Fitotecnia da Universidade Federal de Santa Maria, Santa Maria, situada na Depressão Central do Rio Grande do Sul, com coordenadas geográficas de $29^{\circ} 43^{\prime} \mathrm{S}, 53^{\circ} 43^{\prime} \mathrm{W}$ e $95 \mathrm{~m}$. O solo do local é uma transição entre a Unidade de Mapeamento São Pedro (Argissolo Vermelho Distrófico Arênico) e a Unidade de Mapeamento Santa Maria (Alissolo Hipocrômico Argilúvico Típico) e o clima da região é Cfa (subtropical úmido com verões quentes e sem estação seca definida), conforme classificação de Köppen.

A correção do $\mathrm{pH}$ e a adubação do solo baseou-se na análise de solo da área. Em 15/02/2007 foi aplicado 3,7 tha ${ }^{-1}$ de calcário (PRNT 75,4\%). Nas semeaduras foram utilizados $250 \mathrm{~kg} \mathrm{ha} \mathrm{h}^{-1}$ da formulação 12-32-16 $\left(\mathrm{N}-\mathrm{P}_{2} \mathrm{O}_{5}-\mathrm{K}_{2} \mathrm{O}\right)$. A adubação nitrogenada de cobertura foi parcelada em três vezes (início do perfilhamento, elongação do colmo, emborrachamento), com $100 \mathrm{~kg} \mathrm{ha}^{-1}$ de $\mathrm{N}$, na forma de uréia. O solo foi preparado pelo método convencional, a densidade de semeadura foi $25 \mathrm{~kg} \mathrm{ha}^{-1}$ de sementes, sendo este valor corrigido de acordo com a pureza e o poder germinativo dos genótipos.

O delineamento experimental utilizado foi blocos ao acaso, com quatro repetições. Cada unidade experimental foi composta por cinco fileiras de $4 \mathrm{~m}$ de comprimento, com espaçamento de $0,2 \mathrm{~m}$ entre fileiras. 
Foram utilizados cinco genótipos de azevém: Comum, Fepagro São Gabriel, LE 284, Avance e INIA- Titán, cultivados em cinco épocas de semeadura: 11/05, 07/06, 05/07, 09/08 e 01/09/2007. Foram efetuados diferentes números de cortes antes do diferimento para posterior produção de sementes (um, dois, três e quatro cortes).

Os cortes foram realizados quando a altura do dossel média de três genótipos da mesma época de semeadura atingia em média $20 \mathrm{~cm}$, a seis $\mathrm{cm}$ acima do nível do solo, manualmente com auxílio de uma tesoura. A altura do dossel foi realizada com auxílio de uma régua, sendo a média de cinco medidas por bloco, em $\mathrm{cm}$, tomada do nível do solo até a curvatura das folhas mais altas. Assim, o primeiro corte foi feito em média, entre as diferentes épocas, aos 65 dias após a semeadura, posteriormente o segundo corte foi feito em média aos 26 dias após o primeiro corte, já o terceiro corte em média após 23 dias do segundo corte e o quarto corte em média aos 24 dias após o terceiro corte.

As amostras de forragem provenientes dos cortes foram separadas em folha, colmo e material senescente, pesadas e levadas para estufa de ar forçado a $60^{\circ} \mathrm{C}$, por 72 horas, pesadas novamente, sendo sequencialmente moída em moinho tipo Willey, com peneira de malha 1 $\mathrm{mm}$. A produção total de matéria seca foi obtida pelo somatório das produções dos cortes.

Nas análises bromatológicas, foi determinado o nitrogênio total pelo método micro-Kjeldahl, sendo, posteriormente, multiplicado pelo fator 6,25 para obtenção da proteína bruta, segundo (AOAC, 1984). A fibra em detergente neutro foi determinada conforme (Goering e Van Soest, 1970).

As variáveis dos componentes do rendimento das sementes avaliadas foram rendimento de sementes $\left(\mathrm{kg} \mathrm{ha}^{-1}\right)$ e número de espigas (unidades $\mathrm{m}^{-2}$ ). As variáveis número de espiguetas por espiga, número de sementes por espigueta, comprimento de espigas, espiguetas e sementes $(\mathrm{cm})$ e espaçamento entre espiguetas $(\mathrm{cm})$ foram avaliadas a partir de 40 espigas que foram separadas aleatoriamente por bloco. O peso de mil sementes foi obtido a partir de sementes separadas ao acaso e submetidas à contagem de oito repetições de 100 sementes, conforme Brasil (1992) e pesadas em balança analítica.

As correlações canônicas foram estimadas entre o grupo de variáveis componentes de produção e qualidade de matéria seca (Grupo 1) da forragem e rendimento de sementes (Grupo 2), de acordo com os procedimentos descritos por (Cruz e Regazzi, 1997).
As variáveis explicativas totalizaram 14 variáveis: do Grupo 1 foram matéria seca total, de folha e de colmo, proteína bruta e fibra em detergente neutro e do Grupo 2 foram rendimento de sementes, número de espigas por $\mathrm{m}^{2}$, comprimento de espiga, número de espiguetas por espiga, comprimento de espigueta, número de sementes por espigueta, comprimento de semente, espaçamento entre espiguetas na espiga e peso de mil sementes.

Preliminarmente, foram testados todos os pressupostos: normalidade, linearidade e multicolinearidade. Foram estimados coeficientes de correlação de Pearson (Steel et al., 1997) entre as 14 variáveis. A hipótese de nulidade $\left(\mathrm{H} 0: \mathrm{r}_{1}=\mathrm{r}_{2}=\ldots \ldots=\right.$ $\left.\mathrm{r}_{\mathrm{n}}=0, \mathrm{~s}=\min \{\mathrm{p}, \mathrm{q}\}\right)$ para as correlações canônicas foi testada por meio do teste do qui-quadrado. A hipótese de que o coeficiente de correlação Pearson é igual à zero (H0: 0) foi avaliada pelo teste t. As análises foram realizadas usando os programas computacionais GENES (Cruz, 1997; SAEG, 2007).

\section{Resultados e Discussão}

Observando as correlações de Pearson, verifica-se que os componentes da produção de forragem matéria seca de folhas e matéria seca de colmos foram fortemente correlacionados com a produção de matéria seca total $(0,94$ e 0,82 , respectivamente), mas a correlação entre eles $(0,58)$ teve valor intermediário (Tabela 1). Correlações de Pearson com valor intermediário ocorreram também entre estas três variáveis e as de qualidade da forragem, proteína bruta e fibra em detergente neutro, sendo que as correlações com a proteína bruta foram negativas (Tabela 1).

O rendimento de sementes foi correlacionado (Pearson) com as variáveis do grupo 1 , contudo as correlações com os caracteres de produtividade da matéria seca foram negativas e com as variáveis de qualidade foram positivas (Tabela 1). Isto indica que para que haja maior rendimento de sementes, na utilização do azevém para duplo propósito, deverão ser realizados menos cortes.

As correlações de Pearson entre o rendimento de sementes e as demais variáveis do grupo 2 foram significativas e positivas para número e comprimento de espigas, número de espigueta e peso de mil sementes (Tabela 1). As demais variáveis do grupo $2 \mathrm{em}$ relação as variáveis produtivas matéria seca total, folhas e colmo do grupo 1 se mostraram independentes ou com correlações de valor baixo, exceto para a matéria seca colmo que correlacionou-se negativamente com o comprimento de espiga, número de espigueta e peso de mil sementes (Tabela 1). 
Tabela 1. Coeficientes de correlação simples de Pearson entre os caracteres matéria seca total (MST), matéria seca de folha (MSF), matéria seca de colmo (MSC), proteína bruta (PB), fibra detergente neutro (FDN), rendimento de sementes (REND), número de espigas (NE), comprimento de espiga (CE), número de espiguetas por espiga (NEGTA), comprimento de espigueta (CEGTA), comprimento de semente (CSEM), número de semente por espigueta (NSEM), espaçamento entre espiguetas na espiga (ESP) e peso de mil sementes (PMIL).

\begin{tabular}{|c|c|c|c|c|c|c|c|c|c|c|c|c|c|c|}
\hline & MST & MSF & MSC & PB & FDN & REND & $\mathrm{NE}$ & $\mathrm{CE}$ & NEGTA & CEGTA & CSEM & NSEM & ESP & PMIL \\
\hline MST & 1 & $0,94 *$ & $0,82 *$ & $-0,46^{*}$ & $0,55^{*}$ & $-0,29 *$ & $0,02^{\mathrm{ns}}$ & $-0,19^{*}$ & $-0,08^{\mathrm{ns}}$ & $-0,01^{\mathrm{ns}}$ & $0,09^{\mathrm{ns}}$ & $0,04^{\mathrm{ns}}$ & $-0,09^{\mathrm{ns}}$ & $-0,14^{*}$ \\
\hline MSF & & 1 & $0,58 *$ & $-0,37 *$ & $0,46^{*}$ & $-0,22 *$ & $-0,03^{\mathrm{ns}}$ & $-0,03^{\text {ns }}$ & $0,01^{\mathrm{ns}}$ & $0,06^{\mathrm{ns}}$ & $0,08^{\mathrm{ns}}$ & $0,02^{\mathrm{ns}}$ & $-0,05^{\mathrm{ns}}$ & $0,01^{\mathrm{ns}}$ \\
\hline MSC & & & 1 & $-0,47^{*}$ & $0,57^{*}$ & $-0,33^{*}$ & $-0,01^{\mathrm{ns}}$ & $-0,41 *$ & $-0,19^{*}$ & $-0,11^{*}$ & $0,06^{\mathrm{ns}}$ & $0,08^{\mathrm{ns}}$ & $-0,12 *$ & $-0,37^{*}$ \\
\hline PB & & & & 1 & $-0,68 *$ & $0,47 *$ & $0,30 *$ & $0,29 *$ & $0,18^{*}$ & $0,04^{\mathrm{ns}}$ & $-0,01^{\mathrm{ns}}$ & $0,06^{\mathrm{ns}}$ & $0,14^{*}$ & $0,19^{*}$ \\
\hline FDN & & & & & 1 & $-0,54 *$ & $-0,30 *$ & $-0,37 *$ & $-0,23 *$ & $-0,09 *$ & $-0,04^{\mathrm{ns}}$ & $-0,01^{\mathrm{ns}}$ & $-0,05^{\mathrm{ns}}$ & $-0,31^{*}$ \\
\hline REND & & & & & & 1 & $0,68^{*}$ & $0,26^{*}$ & $0,20 *$ & $0,04^{\mathrm{ns}}$ & $-0,01^{\mathrm{ns}}$ & $0,06^{\mathrm{ns}}$ & $-0,06^{\mathrm{ns}}$ & $0,24 *$ \\
\hline $\mathrm{NE}$ & & & & & & & 1 & $0,01^{\mathrm{ns}}$ & $-0,05^{\mathrm{ns}}$ & $-0,11^{*}$ & $0,05^{\mathrm{ns}}$ & $0,18^{*}$ & $-0,06^{\mathrm{ns}}$ & $0,06^{\mathrm{ns}}$ \\
\hline $\mathrm{CE}$ & & & & & & & & 1 & $0,55^{*}$ & $0,40 *$ & $-0,03^{\mathrm{ns}}$ & $-0,08^{\mathrm{ns}}$ & $0,25^{*}$ & $0,52 *$ \\
\hline NEGTA & & & & & & & & & 1 & $0,33 *$ & $0,02^{\mathrm{ns}}$ & $0,06^{\mathrm{ns}}$ & $0,13^{*}$ & $0,32 *$ \\
\hline CEGTA & & & & & & & & & & 1 & $-0,23 *$ & $0,41^{*}$ & $0,23^{*}$ & $0,17 *$ \\
\hline CSEM & & & & & & & & & & & 1 & $-0,09^{*}$ & $0,05^{\mathrm{ns}}$ & $-0,05^{\mathrm{ns}}$ \\
\hline NSEM & & & & & & & & & & & & 1 & $0,06^{\mathrm{ns}}$ & $-0,11^{*}$ \\
\hline ESP & & & & & & & & & & & & & 1 & $0,16^{*}$ \\
\hline PMIL & & & & & & & & & & & & & & 1 \\
\hline
\end{tabular}

* Significativo em 5\% de probabilidade de erro, pelo teste t.

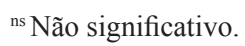

A análise de correlação canônica permite observar que os grupos componentes produtivos da matéria seca da forragem e do rendimento de sementes considerados não são independentes e apenas o primeiro par canônico foi significativo, e, portanto, apenas este é de interesse neste estudo (Tabela 2). As associações intergrupos são estabelecidas, principalmente, pela influência da matéria seca total, de folhas e de colmo, proteína bruta, fibra em detergente neutro, rendimento de sementes, número e comprimento de espiga e peso de mil sementes. O número de espiguetas e sementes, comprimento de espiguetas e sementes, e espaçamento entre espiguetas apresentaram uma baixa contribuição na associação intergrupos.

Observando o primeiro par canônico, pode-se inferir que pastagens de azevém com uma menor produtividade total de matéria seca, mas composta por uma quantidade maior de folhas e menor de colmo, com maior teor protéico e menor teor de fibra em detergente neutro determinam maiores rendimento de sementes, comprimento de espigas e peso de mil sementes, e menor número de espigas. Do ponto de vista do melhoramento, estes resultados apontam para o interesse em selecionar genótipos de ciclo mais longo.
Tabela 2. Correlações canônicas e pares canônicos estimados entre os componentes produtivos da matéria seca e do rendimento de semente.

\begin{tabular}{lc}
\hline \multicolumn{1}{c}{ Caracteres } & $1^{\circ}$ Par Canônico \\
\cline { 2 - 2 } \multicolumn{1}{c}{ Grupo 1 } & \\
\hline Matéria seca total & $-0,53$ \\
Matéria seca de folhas & 0,94 \\
Matéria seca de colmo & $-0,45$ \\
Proteína bruta & 0,15 \\
Fibra em detergente neutro & $-0,73$ \\
\hline & \\
\hline Rendimento de sementes & 0,72 \\
Número de espigas & $-0,15$ \\
Comprimento de espiga & 0,56 \\
Número de espiguetas por espiga & $-0,08$ \\
Comprimento de espigueta & $-0,02$ \\
Número de semente por espigueta & 0,04 \\
Comprimento de semente & 0,11 \\
Espaçamento entre espiguetas & $-0,001$ \\
Peso de mil sementes & 0,34 \\
\hline R & 0,67 \\
Significância & 0,00001 \\
\hline
\end{tabular}


Em gramíneas forrageiras, conforme Araújo e Coulman (2004) a literatura indica que a seleção para um maior rendimento de semente poderia ser conseguida diminuindo a produtividade de matéria seca total, uma vez que estes são negativamente correlacionados.

A remoção de área foliar provoca estresse na planta, e o momento e a intensidade da desfolha afetará em maior ou menor grau a produção de matéria seca e sementes, sendo que no trigo ocorre redução de aproximadamente cinco e $23 \%$ no rendimento de sementes quando manejados com um corte e dois cortes, respectivamente, em comparação ao sistema sem corte (Bortolini et al., 2004).

As pastagens de azevém são produzidas primeiramente para alta produção da matéria seca, com características desejáveis do relvado, sendo que o rendimento de semente varia significativamente entre genótipos (Young et al., 2008).

A desfolha excessiva da planta pode proporcionar redução significativa da área foliar na fase de florescimento, sendo que esta fase é a determinante para a expressão do potencial de rendimento de sementes (Dunphy et al., 1982), portanto, é de extrema importância a realização de um manejo correto.

Alguns genótipos de cereais anuais, como trigo, triticale, cevada e centeio podem ser utilizados no sistema de duplo propósito, quando submetidos a um corte (Bortolini et al., 2004), devido essas plantas possuírem alta capacidade de recuperação da área foliar após desfolhações e à elevada produção de grãos. Esses autores ainda ressaltam que alguns dos genótipos de aveia branca e aveia preta podem ser considerados de alta aptidão ao sistema de duplo propósito, quando submetidos ao sistema de dois cortes.

Cabe ressaltar, que o pastejo ou o corte em plantas forrageiras é prática comum em áreas destinadas à produção de sementes, pois auxiliam a evitar o acamamento devido à menor estatura das plantas, maior perfilhamento e uniformidade de florescimento (Carámbula, 1981; Nabinger, 1981). Salienta-se, portanto, atenção para a intensidade do corte ou pastejo, pois se este for realizado indiscriminadamente pode comprometer o rebrote interferindo no rendimento de sementes, uma vez que este se correlaciona negativamente com a produção de matéria seca total (Tabelas 1 e 2).

Não obstante, Araújo e Coulman (2004) avaliando correlações entre caracteres agronômicos em Bromus riparius Rehm, afirmam que é possível desenvolver simultaneamente genótipos com alta produtividade de matéria seca associados a altos teores protéicos e baixos teores de fibra, e alto rendimento de sementes. Como a correlação entre produção de matéria seca total e rendimento de sementes é negativa, deve-se achar outro caractere que esteja correlacionado com estas visando buscar maior produtividade.

$\mathrm{Na}$ correlação canônica neste estudo, a matéria seca total correlaciona-se negativamente com o rendimento de sementes, indicando dificuldade em aumentar concomitantemente ambos. No entanto, a matéria seca de folhas correlaciona-se positivamente com o rendimento de sementes. Visto que, Flores et al. (2008) ressalta para o azevém, que a variável matéria seca de folhas é considerada o componente mais importante para a planta e para o animal, constituindo dessa forma, a base mais importante das pastagens. Este estudo pode demonstrar um caminho para futuros estudos, ou seja, geneticistas poderão melhorar essa variável para aumentar ambas produtividades.

Correlações da produção de matéria seca total com a proteína bruta foram significativas e negativas, tanto para a correlação de Pearson quanto para canônica (Tabelas 1 e 2). Resultados da literatura indicam que o relacionamento entre produção da matéria seca em plantas forrageiras e a proteína bruta é geralmente negativo (Araújo e Coulman, 2004), corroborando com esse trabalho. As correlações de Pearson e canônica da proteína bruta com fibra em detergente neutro foram significativas e negativas, concordando com Stratton et al. (1979) e Araújo e Coulman (2002), que também observaram resultados semelhantes em plantas forrageiras.

A correlação de Pearson entre rendimento de sementes e número de espigas foi significativa e positiva (Tabela 2). Camargo (1987) também observou correlações positivas para rendimento de sementes com número de espigas para diferentes gerações de cruzamentos de trigo. Perante a isso, Carámbula (1981) comenta que o número de espigas influi diretamente no rendimento das sementes. Adesfolha do trigo pelo animal, conforme Bortolini et al. (2004) contribui para o aumento do número de perfilhos e de espigas, podendo conduzir para um incremento na produção de sementes.

De acordo com Carámbula (1981), acredita-se que o maior rendimento de sementes seja o reflexo da maior quantidade de perfilhos principais com meristemas apicais presentes, o que resulta em maior número e peso de sementes, contribuindo para o maior rendimento. Em trigo, Vieira et al. (2007) relataram que os caracteres número de espigas $(\mathrm{r}=0,64)$, número de sementes/espigueta $(\mathrm{r}=0,87) \mathrm{e}$ peso de mil sementes $(\mathrm{r}=0,33)$ são os principais fatores que determinam o rendimento de sementes.

Considerável quantidade de forragem pode ser removida, 
conforme Bortolini et al. (2004), sem afetar seriamente a produção de grãos, pois apesar da redução do índice de área foliar, a produção de sementes é compensada pelo aumento do número de espigas em cereais de inverno com duplo propósito. O pastejo ou corte causa alterações morfológicas e fisiológicas na planta, como a eliminação da dominância apical na fase de crescimento vegetativo provoca maior perfilhamento que é de grande importância na produção de sementes, haverá maior número de sítios para surgimento de mais inflorescências, logo, mais espigas).

Conforme Carámbula (1981) do ponto de vista prático o rendimento de sementes em espécies forrageiras pode ser definido apenas por dois componentes: número de sementes e peso de mil sementes. Esse autor revela que se considerarmos as diferentes espécies forrageiras, podese afirmar que o principal componente para o azevém é comprimento das espigas, em trevo branco é o número de espigas e em trevo vermelho é número de sementes, e assim, os distintos manejos deverão favorecer em cada espécie o componente mais problemático.

Estes resultados corroboram com os observados para a correlação canônica nesse estudo, em vista que em relação aos componentes do rendimento, as correlações mais altas foram para comprimento de espiga $(0,56)$, seguidos por peso de mil sementes $(0,34)$ e número de espigas $(-0,15)$. Adicionalmente ressalta-se a importância de estudo das correlações canônicas, pois permitem maiores complexidades nos resultados, inferindo em resultados mais precisos. Assim, pode-se concluir que, mesmo as plantas de azevém apresentando maior número de espigas, o seu comprimento e o peso das sementes são fundamentais para contribuir em maiores rendimentos de sementes.

Uma das causas do menor comprimento das espigas, conforme Dunphy et al. (1982), é devido ao pastejo no período de elongação do colmo, pois nessa fase há uma concorrência de fotoassimilados entre colmos, folhas e raízes. O aumento do período de pastejo, segundo Bortolini et al. (2004), determina o menor comprimento da espiga refletindo em menor número de espiguetas por espiga determinante na queda de rendimento de grãos.

Outro fator determinante, conforme Bortolini et al. (2004) é quando os meristemas apicais dos perfilhos são removidos, a produção de sementes é representada pelos perfilhos de segunda ordem, estes são menos produtivos e apresentam espigas de menor tamanho, sementes mais leves, mais sensíveis ao estresses e menor probabilidade de sobrevivência. Deve-se considerar ainda, que a idade dos perfilhos é de extrema importância, uma vez que perfilhos formados mais tardiamente perdem progressivamente a habilidade do desenvolvimento vegetativo em reprodutivo.

Conforme Araújo e Coulman (2004), os perfilhos que aparecem em ordem sucessiva em uma haste mãe/ principal apresentam uma tendência decrescente de produzir inflorescências, e em Bromus mollis produzem maior porcentagem de espigas que os demais perfilhos. Del Duca et al. (1999) observou em trigo com um corte, acréscimo de $15 \%$ no número de espigas e queda de $6 \%$ e $10 \%$ no peso de mil sementes e número de sementes por espiga, respectivamente, em relação ao sem corte, indicando que o aumento no número de espigas não compensou os menores comprimento das espigas e peso de mil sementes.

A correlação de Pearson não foi significativa para produção de matéria seca total e número de espiguetas (Tabela 1).

Para o rendimento de sementes e número de espiguetas a correlação de Pearson foi significativa e positiva (Tabela 1), resultado que foi semelhante ao apresentado em trigo por Camargo (1987). Entretanto, para o comprimento de espiguetas, número e comprimento de semente e espaçamento entre espiguetas a correlação não foi significativa (Tabela 1). Camargo (1987) obteve correlação positiva para rendimento de sementes com número de sementes, diferente deste estudo.

Ainda, em relação à correlação canônica, as variáveis número de espiguetas e sementes, comprimento de espiguetas e sementes, e espaçamento entre espiguetas tiveram pouca contribuição para explicar a associação intergrupos, devido aos baixos valores de seus coeficientes. Acredita-se que esse fato se deve a uma compensação nos componentes de rendimento, quando o acréscimo de um componente é acompanhado por uma redução em outro componente (Sangoi et al., 1997).

Em gramíneas, o número de espiguetas por espiga e o número de sementes por espigueta, assim como seu completo desenvolvimento é definido no período entre a iniciação floral e na emergência da inflorescência sobre a folha bandeira (Carámbula, 1981). Em vista disso, quanto mais cedo se formar uma espiga, maior é o número de primórdios foliares que está se acumulando em seu meristema apical e maior será a possibilidade das axilas dos mesmos formarem espiguetas.

A desfolha no trigo pelo animal contribui também para o aumento do número de perfilhos, podendo conduzir para um incremento na produção de sementes, mas que em contrapartida, a desfolha mais intensa provoca redução nos componentes de rendimento (Bortolini et al., 2004). Segundo os autores, quanto mais se atrasa a data final da 
desfolha, menor será o número de espiguetas por espiga, refletindo em menor quantidade de grãos por espiga. Horn et al. (1994), relatam que neste período ocorre concorrência por fotoassimilados da espiga com os colmos, folhas e raízes, levando a uma diminuição do número de espiguetas por espiga.

Foram observados neste estudo através da correlação de Pearson e a canônica um efeito negativo na correlação entre a matéria seca total e o peso de mil sementes. Os autores Carámbula (1981), Pritsch (1980) e Ahrens e Oliveira (1997) relatam que o peso de mil sementes em pastagens de azevém manejadas com cortes é inferior daquelas que não sofreram cortes. Ou seja, o aumento da matéria seca total diminui o peso de mil sementes, fato que corrobora os dados obtidos neste estudo (Tabela 1 e 2). Carámbula (1981) relata que em Agropyron, o peso de mil sementes apresenta uma correlação positiva com o rendimento de sementes, e negativa com o número de sementes. Este desempenho é similar ao observado neste estudo para correlação de Pearson em azevém.

Neste estudo, não foi observada correlação de Pearson singificativa entre o número de espigas e o peso de mil sementes. Entretanto, na correlação canônica houve um efeito negativo, corroborando com Del Duca et al. (1999) que evidenciam que a desfolha, apesar de causar um aumento no número de espigas, estas não são o bastante para compensar o decréscimo no peso das sementes. Devido à concorrência pelas reservas e fotoassimilados, após o corte ou pastejo em qualquer intensidade, entre folhas, colmos e inflorescência jovem, o destino das reservas tem prioridade para folhas e colmos e, de alguma maneira, retarda o crescimento da inflorescência, e como consequência, reduz a taxa de sobrevivência de perfilhos, o número de espiguetas por espigas e o peso de mil sementes (Bortolini et al., 2004).

\section{Conclusões}

A produção de matéria seca total das pastagens de azevém correlaciona-se negativamente com o rendimento de sementes. A associação entre caracteres agronômicos produtivos da matéria seca e do rendimento de semente é critério de fundamental importância na seleção de genótipos para o azevém. O rendimento de sementes correlaciona-se positivamente com a produção de matéria seca de folhas, teor de proteína bruta, comprimento de espiga e peso de mil sementes.

\section{Referências}

AHRENS, D.C.; OLIVEIRA, J.C. Efeitos do manejo do azevém-anual (Lolium multiflorum Lam.) na produção de sementes. Revista Brasileira de Sementes, v.19, n.1, p.41-47, 1997. http://www.abrates.org.br/revista/ artigos/1997/v19n1/artigo08.pdf

AOAC - ASSOCIATION OF OFFICIAL ANALYTICAL CHEMISTS Official methods of analysis. 14.ed. Arlington Virginia, 1984. 1141p.

ARAUJO, M.R.A.; COULMAN, B.E. Genetic variation, heritability and progeny testing in meadow bromegrass. Plant Breeding, v.121 p.417424,2002

ARAUJO, M.R.A.; COULMAN, B.E. Genetic variation and correlation of agronomictraits in me adow bromegrass (Bromus riparius $\mathrm{Rhem}$ ) clones. Ciência Rural, v.34, p.505-510, 2004. http://www.scielo.br/pdf/ $\mathrm{cr} / \mathrm{v} 34 \mathrm{n} 2 / \mathrm{a} 26 \mathrm{v} 34 \mathrm{n} 2 . \mathrm{pdf}$

BORTOLINI P.C.; SANDINI I.; CARVALHO P.C.F.; MORAES, A Cereais de Inverno submetidos ao corte no sistema de duplo propósito. Revista Brasileira de Zootecnia, v.33, p.45-50, 2004. http://www.scielo. br/pdf/rbz/v33n1/a07v33n1.pdf

BRASIL. Ministério da Agricultura e Reforma Agrária. Secretaria Nacional de Defesa Agropecuária. Departamento Nacional de Produção Vegetal. Coordenação de Laboratório Vegetal. Regras para Análise de Sementes. Brasília, DF, 1992. 365p.

CAMARGO, C.E.O. Melhoramento do trigo: XIII. Estimativas de variância, herdabilidade e correlações em cruzamentos de trigo para produção de grãos e tolerância à toxicidade de alumínio. Bragantia, n.46, v.1, p.73-79, 1987. http://www.scielo.br/pdf/brag/v46n1/09.pdf

CARAMBULA, M. Producción de semillas de plantas forrajeras. Montevideu: Hemisfério Sur, 1981. 518p.

CRUZ, C.D.; REGAZZI, A.J. Modelos biométricos aplicados ao melhoramento genético. 2.ed. Viçosa: UFV, 1997. 390p.

DEL DUCA, L.J.A. MOLIN, R.; SANDINI, I Experimentação de genótipos de trigo para duplo propósito na Paraná, em 1999. Passo Fundo: Embrapa Trigo, 2000. 28p. (Embrapa Trigo. Boletim de Pesquisa, 6).

DUNPHY, D.J.; MCDANIEL MEHOLT, E.C. Effect of forage utilization on wheat grain yield. Crop Science, v.22, p.106-109, 1982.

FLORES, R.A.; AGNOL, M.D.; NABINGER, C.; MONTARDO, D.P. Produção de forragem de populações de azevém anual no estado do Rio Grande do Sul. Revista Brasileira de Zootecnia, v.37, n.7, p.1168-1175, 2008 http://www.scielo.br/pdf/rbz/v37n7/05.pdf

FREITAS, F.A.; OLIVEIRA, A.C.; CARVALHO, F.I.F. Análise multivariada de populações de azevém (Lolium multiflorum L.) em diferentes regimes de água. Revista Brasileira de Agrociência, v.9, n.1, p.17-23, 2003. http://www.ufpel.tche.br/faem/agrociencia/v9n1/ artigo02.pdf 
GOERING, H.K.; VAN SOEST, P.J. Forage fiber analysis: apparatus reagents, procedures and some applications. Washington: USDA/ARS, 1970 (Agricultural Handbook, n.379.).

HORN, G.; KRENZER, G.; BERNARDO, D.; REDMON, L.; ANDRAE, J. Evaluation of wheatvarieties in the wheat grain - stocker cattle enterprise. In: Proceeding Annual Wheatland Stocker Conference, 8., 1994, Oklahoma. Proceedings. Oklahoma: CSIRO, 1994, p.211-236.

KENDALL, M. Multivariate analysis. [S. 1.]: Charles Griffing, 1980. 210p.

NABINGER, C. As sementes de forrageiras temperadas no Brasil: situação e perspectivas. Revista Brasileira de Sementes, v.3, n.1, p.51-72, 1981.

NORO, G.; SCHEFFER-BASSO, S.M.; FONTANELI, R.S.;ANDREATTA,

E. Gramíneas anuais de inverno para produção de forragem: avaliação preliminar de cultivares. Agrociência, v.7, n.1, p.35-40, 2003.

PRITSCH, O.M. Épocas de siembra y manejo de cortes en la producción de semillas de raigrás anual cv. La Estanzuela 284. Investigaciones Agronômicas, v.1, n.1, p.18-23, 1980.

SAEG. Sistema para Análises Estatísticas, Versão 9.1: Fundação Arthur Bernardes - UFV - Viçosa, 2007.

SANGOI, L. ALMEIDA, M.L.; ENDER, M. Vantagens e limitações da utilização de ideotipos no melhoramento de plantas de lavoura. Pesquisa Agropecuária Brasileira, v.3, n.1, p.73-80, 1997.
SILVA, J.W. Correlações canônicas de características agroindustriais em cana-de-açúcar. Acta Scientiarum Agronomy, v.29, n.3, p.345-349, 2007.

STEEL, R.G.D.; TORRIE, J.H.; DICKEY, D.A Principles and procedures of statistics: a biometrical approach. New York: McGrawHill Book, 1997. 666p.

STRATTON, S.D.; SLEPER, D.A.; MATCHES, A.G. Genetic variation and interrelationships of in vitro dry matter disappearance and fiber content in orchardgrass herbage. Crop Science, v.19, p.329-333, 1979.

TRUGILHO, P.F. Correlação canônica das características químicas e físicas da madeira de clones de Eucalyptus grandis e Eucalyptus saligna. Cerne, v.9, n.1, p.66-80, 2003. http://www.dcf.ufla.br/cerne/artigos/1302-20094403v9_n1_artigo\%2008.pdf

VIEIRA, E. A. et al. Análise de trilha entre os componentes primários e secundários do rendimento de grãos em trigo. Revista Brasileira de Agrociência, v.13, n.02, p.169-174, 2007. http://www.ufpel.edu.br/faem/ agrociencia/v13n2/artigo05.pdf

YOUNG-KI JO, R.B., WILLIAM P., SCOTT WARNKE, S.C.S.; GEUNHWA, J. Comparative analysis of multiple disease resistance in ryegrass and cereal crops. Theoretical and Applied Genetics, v.117, n.4, 531-543, 2008. 